\title{
Improving Treatment Adherence and Control Rate of Patient with Hypertension Using Aweb-Based Management System in a Rural Community in China
}

\section{Yanxia Zhu}

Chinese PLA General Hospital

Liangm Guo

Chinese PLA General Hospital

Tianran Wu

Monash Medical Center (clayton)

Xingli Wu ( $\nabla$ wxl301@yahoo.com )

National Geriatric Center, Chinese PLA General Hospital

\section{Research Article}

Keywords: Chro nic diseases, Hypertension, Web based management, Community health service, Adherence to medicine

Posted Date: November 12th, 2021

DOI: https://doi.org/10.21203/rs.3.rs-1033178/v1

License: (c) (i) This work is licensed under a Creative Commons Attribution 4.0 International License. Read Full License 
Improving treatment adherence and control rate of patient with hypertension using aweb-based management system in a rural community in China

Yanxia Zhu, BS ${ }^{\mathrm{a} \#}$; Liangmei Guo, $\mathrm{MS}^{\mathrm{a}}$; Tianran $\mathrm{Wu}, \mathrm{MD}^{\mathrm{b} *}$; Xingli $\mathrm{Wu}, \mathrm{MD}^{\mathrm{a}, \mathrm{c}, *}$

a. Department of Health Care, the 2nd Medical Center \& National Geriatric Center, Chinese PLA General Hospital, Beijing, PR China,100853.

b. Department of Emergency, Monash Medical Center (clayton), Melbourne, Australia, $3168 .$.

c. Institute of Geriatric Cardiology, Chinese PLA General Hospital, Beijing, PR China,100853.

* Corresponding Author.

\# Authors devote equally to the article.

\title{
Address for correspondence:
}

Xingli Wu, MD, Department of Health Care, National Geriatric Center, the 2nd Medical Center; Institute of Geriatric Cardiology, Chinese PLA General Hospital, Beijing, PR, China,100853. Email: wx1301@yahoo.com, phone:86-13371619059.

Tianran Wu, MD, Department of Emergency, Monash Medical Center, Melbourne, Australia.Email: wutianran8899@yeah.net.

\begin{abstract}
The control rates of patients with hypertension remain extremely low in Chinese rural communities, therefor we aimed to improve treatment adherence and control rate for patients with hypertension by using a web-based management system, which included modeles of the user's personal information, health education, adherence alerting, communication between physician and statistics analysis and data print functions. 350 patients with uncontrolled hypertension were included in the study through a multi-stage stratified sampling, and were divided radomis1y into the web-based intervention group and control group. Comparing with those in the control group, there was a significant improvement in the control rate of the blood pressure in the intervention group $(93.7 \%$ vs $50.9 \%, \mathrm{p}<0.001)$ and a remarkable decrease in blood pressure (systolic blood pressure declined by $25.0 \mathrm{mmHg},<0.001$; diastolic blood pressure declined by $8.7 \mathrm{mmHg}$, p < 0.001) after 12 months follow-up. The medication adherence rate in intervention groups was improved significantly than that in the control group $\mathrm{p}<0.01)$, and the adherence scale correlated negatively with blood pressure $(\mathrm{r}=-0.518, \mathrm{P}<0.001)$, and positively correlated with control rate (0.623, $\mathrm{P}<0.001)$. This study suggested that the web-based hypertension management system is worth spreading in rural areas in developing countries.
\end{abstract}

Keywords: Chronic diseases, Hypertension, Web-based management, Community health service, Adherence to medicine 


\section{Introduction}

Hypertension is the most important risk factor for cardiac-cerebral vascular disease and remains an important public health challenge in the world [1, 2]. The morbidity of hypertension in adults was $26.8 \%$ for males and $25.4 \%$ for females in urban areas, and $24.2 \%$ for males and $22.8 \%$ for females in suburban areas in China [3]. Furthermore, an increasing prevalence of hypertension was observed in China from 2002 to 2012, especially in rural areas.

Fortunately, there has been an improvement regarding the knowledge of hypertension risk factors, percentages of patients receiving specific medications, and numbers of patients with controlled hypertension in some developed countries [4,5]. However, according to a survey conducted in 2013 in China, although there are constantly updated guidelines and a spectrum of potent medications, only $37 \%$ of hypertensive patients in rural communities and $30 \%$ in cities were able to have their blood pressure controlled after taking medications [3]. The overall rates of awareness, treatment, and control of hypertension were $52.7 \%, 47.9 \%$ and $17.9 \%$ in urban areas and $39.5 \%, 33.4 \%$, and $9.2 \%$ in rural areas respectively. The poor blood pressure control, in turn, has been shown to increase the risk of myocardial infarction, renal disease, stroke and premature death [6].

Multiple factors contributing to less than ideal blood pressure control have been described, including the quality of life, the complexity and side effects of medications, health care system issues, patient demographics, behaviors, treatments, and clinical variables [7]. Among these factors, the lack of knowledge regarding hypertension and the nonadherence to prescribed therapies were mostly realized. A meta-analysis revealed that the odds of good blood pressure control among those who were adherent to therapies, compared to those who were not, were 3.44 (95\% confidence interval 1.6-7.37) [8]. It is mostly agreed that patient non-adherence to antihypertensive treatment recommendations remains a global problem, and promoting patient adherence is a major clinical hurdle that is necessary to decrease cardiovascular morbidity and mortality $[9,10]$.

Obviously, there is a need for a valid, reliable, and cost-effective tool that is accepted by both health care providers and patients for blood pressure control monitoring to promote adherence[11,12]. In fact, many countries have been focusing on a convenient and economical mobile-phone or computer-based solution for the control of the disease by improving patients' knowledge of hypertension and promoting their adherence to anti-hypertensive medications [13-15].

Nevertheless, there is some evidence of publication biases in favor of positive results. Therefore, more research is needed to understand the impact of such interventions on patients and providers, as well as their perceptions of such interventions. It is especially important that these studies are conducted in low and middle-income countries who contributed to eighty percent of the global burden of the disease [16,17].

The primary objective of the current study is to develop a web-based management system for patients with hypertension and evaluate its effectiveness in the 
rural community in China.

\section{Methods}

\section{Patients enrollment:}

This was a pragmatic randomized controlled trial comparing the web-based interventions in addition to usual care versus usual care alone in adults with hypertension. Individuals aged 35 years and above with high blood pressure (systolic $\geq 140 \mathrm{mmHg}$ or diastolic $\geq 90 \mathrm{mmHg}$ ) based on three readings from 3 separate days, or receiving antihypertensive medications) were chosen as the candidates. BP was measured at baseline and 12-month post-intervention. A total of 350 participants were randomly recruited in the study through a multi-stage stratified sampling in a rural community of the Huoxian town in Beijing from December 2014 to December 2016. All the participants received questionnaires and physical examinations. The ethics committee of PLA general hospital in China approved the study. We confirm that all methods were performed in accordance with the Declaration of Helsinki and the Chinese Guidelines for Prevention and Treatment of Hypertension 2010 revised edition. All participants gave written informed consent before data collection.

Investigators explained the program to everyone who consented to participate. The baseline interview was conducted to gather the patient's demographic information, medical history and medication adherence with a community health worker. Patients were excluded if they had cerebral hemorrhage, unstable angina, malignant hypertension, or were pregnant.

\section{Informatics platform development}

Based on the Chinese guidelines and consensus for managements of hypertension, a internet platform was developed [18]. The homepage of the internet platform is a user-friendly interface which shows a patient's personal information and the description of the patient's illness. The user list is shown in the list view control on the left, and medical personnel can click the "patients" button on the menu to add a user and display them in the list view control. The Tab frame control consists of eight separate tabs. The "Overview" tab shows the user personal information. The "Clinical document" tab shows the personal illness description. The health education tab shows the education program including acknowledgements regarding hypertension care, hypertension treatment, lifestyle changes, stress and treatment regimen to foster medication adherence. The alerting tab shows whether the blood pressure was within their target and when to measure blood pressures again. The communication tab allows effective communication between the physician and patients to improve understanding regarding hypertension and its treatment. The secure messaging tab offers a protecting system for patient's privacy. The document can only be created and modified by the community physician in charge, and it can be viewed by the physician in charge or the investigator who has been authorized. The statistics analysis tab and the data print 
functions are designed for physician use only.

\section{Patients intervention}

Participants in the intervention group were provided with access to the web portal where they could obtain further information about hypertension. Patients were offered a validated home blood pressure monitor (Omron, M6) and requested to take their blood pressure and to report their readings online or by telephone in the morning.

Physicians, via the internet, text messages or telephones, review blood pressure readings, remind patients to take drugs, arrange follow-up appointment, urge patients to quit smoking, recommend to take low salt and low-fat diet, encourage to maintain proper exercise, suitable weight, stable emotion and plenty of sleep. A cardiologist was invited to give monthly lectures to patients and their family members to elevate their knowledge about the prevention and control of high blood pressure. Meanwhile, patients in the control group received conventional intervention only.

\section{Follow-up of blood pressure control and treatment adherence}

Patients underwent follow-ups every 3 months for up to 12 months and blood pressure was measured during each follow-up. The primary goal of the study was to achieve a hypertension treatment target of below 140/90 $\mathrm{mmHg}$.

Blood pressure is measured at least three times at $5 \mathrm{~min}$ intervals using the appropriate cuff size and a Digital Automatic Blood Pressure Monitor (OMRON HEM-907, OMRON Healthcare Company, Kyoto, Japan) according to a standardized protocol by using the right arm with the patient sitting for all measurements $[19,20]$. The average of the measurements was calculated and used in the analyses. Blood pressure was considered to be uncontrolled if the mean of the systolic pressure was greater than or equal to $140 \mathrm{~mm} \mathrm{Hg}$ or the mean of the diastolic pressure was greater than or equal to $90 \mathrm{~mm} \mathrm{Hg}$.

Medication adherence was measured with the self-reported eight-item scale developed by Morisky, which addresses the circumstances surrounding adherence behaviours[7]. The theory underlying this measure was that failure to adhere to a medication regimen could occur due to several factors as elicited by the questions like"do you sometimes have problems remembering to take your medication", "how often do you have difficulty remembering to take all your blood pressure medication". It was shown to be reliable and the responses were significantly associated with the achieved control of a series of chronic diseases [21,22].. The total score is a summary of all items and ranges between 0 and 8 , with higher scores reflecting higher adherence and lower scores reflecting lower adherence.

\section{Statistical Analysis}

A descriptive analysis was performed to compare the characteristics of the 
subjects in the intervention and control groups. Continuous measures will be compared using Student's $t$-test. Between-group differences in control rate of hypertension will be compared using the $\chi^{2}$ test.The correlation among the adherence, the blood pressure value and controlled hypertension was analyzed using the Pearson correlation method. All analyses were conducted using SPSS (version 19.0), $\mathrm{p}<0.05$ was regarded as statistically significant.

\section{Results}

\section{Baseline characteristics of participants}

A health assessment questionnaire and a high blood pressure survey were completed. The information obtained from these forms included demographics, smoking status and the diagnosis of diabetes, hyperlipidemia and hypertension. The baseline characteristics of the 350 participants in the study are presented in Table 1 . The parameters of respondents in the control and intervention groups are not statistically different as followed: for age was 62.6: 63.7, male gender 51.4\%: 50.3\%, smoking 17.7\%: 19.4\%, High LDL 16.6\%: 17.7\%, Diabetes 9.7\%: 8.6\%.

Table 1.Baseline characteristics

\begin{tabular}{lllll}
\hline & Control $(\mathrm{n}=175)$ & Intervention $(\mathrm{n}=175)$ & t or $\mathrm{X}^{2}$ & $\mathrm{p}$ \\
\hline Age, years (SD) & $62.63(9.34)$ & $63.73(9.74)$ & -1.068 & 0.286 \\
Male, No. (\%) & $90(51.4)$ & $88(50.3)$ & 0.046 & 0.831 \\
Smoking, No. (\%) & $31(17.7)$ & & & \\
& & $34(19.4)$ & 0.17 & 0.68 \\
High LDL, No. (\%) & $29(16.6)$ & $31(17.7)$ & 0.080 & 0.777 \\
& & & & \\
Diabetes, No. (\%) & $17(9.7)$ & $15(8.6)$ & 0.138 & 0.711 \\
\hline
\end{tabular}

LDL:low density lipoprotein.

\section{The comparison of blood pressure control rate after 12}

\section{months follow-up}

After 12-month follow-up, the patients with blood pressure under control in the intervention group was higher than that in the control group $(93.7 \%$ : 50.9\%, $\chi 2, p$ $<0.01)$. 


\section{The medication adherence change after 12 months follow-up}

The baseline mean score for the medication adherence scale in both the groups was not statistically different. At 12-month follow-up, the medication adherence score in the intervention group was higher than that in the control group (6.59: 4.84, $\mathrm{p}<0.01$ ) and the baseline value of the intervention group (6.59: 4.05, $\mathrm{p}<0.01)$. The medication adherence score in the control group was higher than its baseline value at 12-month follow-up (4.84: 4.39, $\mathrm{p}=0.046$ ) (Table 2).

Table 2.The medication adherence score pre- and post-12 months follow-up

\begin{tabular}{clllll}
\hline groups & $\mathrm{n}$ & Pre- & Post- & $\mathrm{t}$ & $\mathrm{p}$ \\
\hline Intervention & 175 & $4.051(1.808)$ & $6.594(1.305)$ & -14.851 & 0.001 \\
Control & 175 & $4.394(2.101)$ & $4.840(2.059)$ & 2.005 & 0.046 \\
$\mathrm{t}$ & & -1.637 & -9.359 & & \\
& & & & & \\
$\mathrm{p}$ & & 0.103 & 0.000 & & \\
\hline
\end{tabular}

\subsection{Blood pressure changes}

The baseline mean values of systolic blood pressure and diastolic blood pressure in both groups were not statistically different. There was a significant decrease in blood pressure in both groups at 12-month follow-up. Compared with the control group, the intervention group achieved significantly lower blood pressures (systolic blood pressure differed by $25.0 \mathrm{mmHg}, \mathrm{p}<0.001$, and diastolic blood pressure differed by 8.7 mmHg p <0.001) (Table 3).

.Table 3. Blood pressure changes after 12 months follow-up (mean $\pm s$ )

\begin{tabular}{|c|c|c|c|c|c|c|c|c|c|}
\hline \multirow[t]{2}{*}{ group } & \multirow[t]{2}{*}{ r } & \multicolumn{2}{|c|}{ SBP } & \multirow[b]{2}{*}{$\mathrm{t}$} & \multirow[b]{2}{*}{$\mathrm{p}$} & \multicolumn{2}{|c|}{ DBP } & \multirow[b]{2}{*}{$\mathrm{t}$} & \multirow[b]{2}{*}{$\mathrm{p}$} \\
\hline & & Pre- & Post- & & & Pre- & Post- & & \\
\hline Intervention & 175 & $\begin{array}{l}153.34 \\
(5.484)\end{array}$ & $\begin{array}{l}113.12 \\
(23.10)\end{array}$ & 19.13 & 0.000 & $\begin{array}{l}93.19 \\
(5.55)\end{array}$ & $\begin{array}{c}70.70 \\
(15.07)\end{array}$ & 18.54 & 0.000 \\
\hline control & 175 & $\begin{array}{l}154.85 \\
(12.78)\end{array}$ & $\begin{array}{l}138.18 \\
(30.74)\end{array}$ & 6.62 & 0.000 & $\begin{array}{l}94.03 \\
(5.56)\end{array}$ & $\begin{array}{c}79.38 \\
(18.29)\end{array}$ & 10.14 & 0.000 \\
\hline $\mathrm{t}$ & & 0.997 & -8.624 & & & 0.687 & 4.845 & & \\
\hline $\mathrm{P}$ & & 0.319 & 0.000 & & & 0.158 & 0.000 & & \\
\hline
\end{tabular}

SBP: systolic blood pressure. DBP: diastolic blood pressure. 


\section{The correlation analysis of adherence}

The correlation analysis showed that the patients who scored higher on the adherence scale were more likely to have their blood pressure under control compared with patients who scored lower. The adherence scale was significantly correlated with the control rate and the blood pressure $(\mathrm{p}<0.01)$. (Table 4$)$.

Table 4. The correlation of adherence with control rate and value of blood pressure $(n=350)$

\begin{tabular}{cccc}
\hline & $\mathrm{r}$ & $95 \% \mathrm{CI}$ & $\mathrm{p}$ \\
& & & \\
\hline Controlled & 0.623 & $0.582 \sim 0.662$ & 0.000 \\
& & & \\
SBP & -.519 & $-.473 \sim-.558$ & 0.000 \\
& & & \\
DBP & -.518 & $-.475 \sim-.561$ & 0.000 \\
& & &
\end{tabular}

\section{Outcome of cardiovascular events}

No death was detected, 1 case of unstable angina and 1 cases of ischemic cerebrovascular disease was encountered in both the two groups, with no statistically significant difference $(\mathrm{p}>0.05)$.

\section{Discussion}

Hypertension is still the leading contributor to the global burden of disease and mortality [23,24]. This figure is expected to increase in the following years in some developing countries, and a significant difference in the overall pooled prevalence between urban and rural populations was widely demonstrated [25,26].

Hypertension is also a major cause of cardiovascular disease and the prevalence has increased significantly during recent decades as reported in periodic nationwide surveys made in China [18,27]. According to the 2013-2014 survey, 27.8\% of Chinese adults were hypertensive. Of those treated, $34.6 \%$ had their blood pressure properly controlled, resulting in an overall control rate of $9.7 \%$ among those with hypertension. The control rate is worse in rural areas than in urban areas [28].

Many barriers to low awareness (diagnosis), treatment and control of hypertension in the level of individual, health services and social factors have been identified. They include the knowledge of risk factors by health care workers, availability of equipment for measuring BP, quality, availability and expertise of healthcare providers, patient age, distance to healthcare, socioeconomic status, tobacco use, and adherence to medications $[27,29,30]$.

In rural areas in China, for those receiving community based management, a few factors affecting BP control have been identified. They include annual income, body 
weight, family history of hypertension, antihypertensive medicine awareness, and the number of times of receiving antihypertensive medicine advice [31,32].

Obviously, patient non-adherence to antihypertensive treatment recommendations remains a global problem, and promoting patient adherence is a major clinical hurdle that is necessary to decrease cardiovascular morbidity and mortality $[9,10]$,. This is also seen in other chronic diseases with only $30 \%$ of adherence rates to lifestyle modification and to recommended medicines even after 6 months of therapy [33,34].

It is well recognized in different races that the low control rate of hypertension is influenced individually by adherence to medication [27,35]. In the same way, adherence to appropriate medical therapy for hypertension could result in controlled blood pressure and reduction in adverse outcomes as found in a systematic review that sub-optimal adherence to prescribed treatments is associated with an increased risk of blood-pressure-related complications and mortality [36]. A recent meta-analysis of white and black people reported that black adults have higher rates of hypertension and lower rates of blood pressure control than white adults, mainly because of low antihypertensive regimen adherence, which prevents improved BP control [37].

In fact, even with the effective use of updated guidelines, and new medications, the lack of control of high blood pressure is still a big challenge for many patients and doctors. It is reported that in rural China, no difference was found in BP control had the patients received the so-called standardized management[32]. The failure to satisfactorily address hypertension management needs within our current healthcare system means that new and more efficient approaches to healthcare delivery are needed.

Evidence has suggested the effectiveness of technology in supporting lifestyle changes, such as smoking cessation and weight loss. For chronic disease control, many countries are exploring a greater use of technologies, like the internet, remote monitoring, and telephone support as a way of expanding provision and increasing access to care for a larger number of people at relatively low cost $[38,39]$.

However, there is some evidence of publication bias in favor of positive results, for few rigorous pragmatic studies have been done on the implementation of this approach in the real world $[40,41]$

For blood pressure control, interventions delivered via mobile-phone management system have the potential to improve adherence to treatment, though more research is needed in various races and settings [42]. Computer-based solutions have also been devised for the control of the disease by promoting their adherence to anti-hypertensive medications[39,43]. Most of the solutions have shown to be acceptable, relevant and useful to a broad range of participants [42].

In our study, with the computer-based management system, the medication adherence in intervention groups was elevated significantly than that in control groups at 12-month follow-up ( $<0.01)$. Compared with those in the control group, there are a significant improvement in the control rate of the blood pressure in the intervention group (93.7\%: 50.9\%, $\mathrm{p}<0.001$ ) and a significantly lower blood pressure (systolic blood pressure differed by $25.0 \mathrm{mmHg},<0.001$; diastolic blood pressure differed by 8.7 $\mathrm{mmHg},<0.001)$. The result is consistent with most studies published [39]. 
The correlation analysis showed that patients who scored high on the adherence scale had lower blood pressure when compared with patients who scored low ( $\mathrm{r}=-0.518$, $\mathrm{P}<0.001)$. The adherence scale was also significantly correlated with control rate $(0.623, \mathrm{P}<0.001)$. This result agreed with the findings by other authors who declared that adherence to appropriate medical therapy for hypertension can result in controlled blood pressure and reduction in adverse outcomes [44].

The satisfactory BP control rate in our study may come from a systemic understanding of the main barrier to medicine adherence.

On the health service organization level, participants commonly described a range of negative factors influencing their adherent behaviors, which include long waiting times, frequent and unexplained changes to patient flow systems, unresponsive clinical care, unprofessional health worker practices [45]. This can be effectively resolved by the elaborately designed interaction net system. Based on the feedbacks generated by the software, both participants and physicians were automatically informed whether the blood pressure was within their target, when to take the blood pressure again, and what to do if the blood pressure was too high or too low. The physicians in charge will actively follow the patient blood pressure, give timely appointment of subsequent visits if the targeted blood pressure was not reached.

On the patients' level, reported problems that negatively influenced adherence include unhealthy refractory lifestyle, depression, lack of knowledge regarding hypertension and its treatment, complexity of medication regimen, side effects of medication, forgetting or reluctance to take medications, and unwillingness to adopt a greater role in their disease management $[7,46]$.

This may be resolved by face to face talks given monthly by physicians and information on the education section of the platform. The education content involves improving the awareness of the patient of hypertension care, correcting misunderstandings and incorrect beliefs regarding hypertension treatment, reducing stress, establishing a simple treatment regimen, and encouraging the willingness to play a greater role in their disease management to foster medication adherence. The in-depth communication with those who had been struggling with adherence to achieve better BP control was conducted by providing practical and emotional support.

In conclusion, prompts via the web-based management system may improve adherence to appropriate medical therapy for patients with hypertension, which in turn can result in controlled blood pressure and reduction in adverse outcomes. Undoubtedly, the web-based adherence interventions should be underpinned with behavior change theories. The complex mix of patient psychosocial factors and healthcare services invariably affect adherence. All the facilitators and barriers encountered with the web-based management system should be closely examined. That is especially important for low socioeconomic settings.

Acknowledgments: The authors would like to express their special thanks to the staff at the Department of Cardiology for their kind cooperation when conducting this study. 


\section{References}

1. Go AS, Bauman MA, Coleman King SM, Fonarow GC, Lawrence W, et al. An effective approach to high blood pressure control: a science advisory from the American Heart Association, the American College of Cardiology, and the Centers for Disease Control and Prevention. J Am Coll Cardiol.2014;63:1230-1238.

2. Jafar TH, et al. Control of blood pressure and risk attenuation: a public health intervention in rural Bangladesh, Pakistan, and Sri Lanka: feasibility trial results. $J$ Hypertens. 2016;34:1872-1881.

3. Zhou M, et al. Cause-specific mortality for 240 causes in China during1990-2013: a systematic subnational analysis for the Global Burden of Disease Study 2013.

Lancet. 2016;387(10015):251-272.

4. Moser M, Franklin SF. Hypertension management: results of a new national survey for the Hypertension Education Foundation: Harris Interactive. J ClinHypertens (Greenwich). 2007;9:316-323.

5. Ong KL, et al. Prevalence, awareness, treatment, and control of hypertension among United States adults 1999-2004. Hypertension. 2007;49:69-75.

6. Campbell NR, Lackland DT, Niebylski ML:

World Hypertension League Committee; International Society of Hypertension Executive Committee. High blood pressure: why prevention and control are urgent and important: a 2014 fact sheet from the World Hypertension League and the International Society of Hypertension. J Clin Hypertens (Greenwich).2014;16:551-553.

7. MoriskyDE, Geren LW, Levine DM .Concurrent and predictive validity of a self-reported measure of medication adherence. Med Care.1986;24:67-77.

8. DiMatteo MR, Giordani PJ, Lepper HS, Croghan TW. Patient adherence and medical treatment outcomes: a meta-analysis. Med Care. 2002;40:794-811.

9. Hamilton GA. Measuring adherence in a hypertension clinical trial. Eur J Cardiovasc Nurs. 2003;2:219-228.

10. Wogen J, French F. Patient adherence with hypertension medication. J Manag Care Pharm. 2004;10:90-101.

11. Lim SS, et al. A comparative risk assessment of burden of disease and injury attributable to 67 risk factors and risk factor clusters in 21 regions, 1990-2010: a systematic analysis for the Global Burden of Disease Study 2010. Lancet. 2012;380(9859):2224-2260.

12. Lawes CM, Van der Hoorn S, Rodgers A. International Society of Hypertension. Global burden of blood-pressure-related disease, 2001. Lancet. 2008;371(9623):1513-1518

13. Gurol-Urganci I, de Jongh T, Vodopivec-Jamsek V, Atun R, Car J. Mobile phone messaging reminders for attendance at health care appointments.Cochrane Database Syst 
Rev. 2013;12:CD007458.

14. Leon N, Schneider H, Daviaud E. Applying a framework for assessing the health system challenges to scaling up mHealth in South Africa. BMC Med Inform DecisMak. 2012;12:123.

15. Tomlinson M, Rotheram-Borus MJ, Swartz L, Tsai AC. Scaling up mHealth: Where is the evidence? PLoS Med. 2013;10:e1001382.

16. Aranda-Jan CB, Mohutsiwa-Dibe N, Loukanova S. Systematic review on (mHealth) projects in Africa. BMC Public Health. 2014;14:188.

17. Gwadry-Sridhar FH, Manias E, Lal L, Salas M, Hughes DA, Ratzki-Leewing A, et al. Impact of interventions on medication adherence and blood pressure control in patients with essential hypertension: a systematic review by the ISPOR Medication Adherence And Persistence Special Interest Group. Value Health. 2013;16:863-871.

18. Wang JG. Chinese Hypertension Guidelines.Pulse (Basel). 2015;3:14-20.

19. Hou Z, Meng Q, Zhang Y. Hypertension Prevalence, Awareness, Treatment, and Control Following China's Healthcare Reform. Am J Hypertens. 2016;29:428-431.

20. Agyemang C, Bruijnzeels MA, Owusu-Dabo E. Factors associatedwith hypertension awareness, treatment, and control in Ghana, WestAfrica. J Hum Hypertens. 2005;20:67-71.

21. Kim MT, Hill MN, Bone LR, Levine DM. Development and testing of the Hill-Bone Compliance to High Blood Pressure Therapy Scale. Prog Cardiovasc Nurs. 2000;15:90-96.

22. Reynolds K, et al. Validation of the Osteoporosis-Specific Morisky Medication Adherence Scale in long-term users of bisphosphonates. Qual Life Res. 2014; 23:2109-2120.

23. Kearney PM, Whelton M, Reynolds K, Muntner P, Whelton PK, He J. Global burden of hypertension: analysis of worldwide data. Lancet. 2005;365:217-223.

24. Anchala R, et al. Hypertension in India: a systematic review and meta-analysis of prevalence, awareness, and control of hypertension. J Hypertens. 2014;32:1170-1177.

25. Gupta R. Convergence in urban-rural prevalence of hypertension in India. J Hum Hypertens. 2016;30:79-82.

26. Sarki AM, Nduka CU, Stranges S, Kandala NB, Uthman OA. Prevalence of Hypertension in Low- and Middle-Income Countries: A Systematic Review and Meta-Analysis. Medicine (Baltimore). 2015; 94:e1959.

27. Wang J, Zhang L, Wang F, Liu L, Wang H; China National Survey of Chronic Kidney Disease Working Group.Prevalence, awareness, treatment,and control of hypertension in China: results from a national survey.Am J Hypertens. 2014;27:1355-1361.

28. Li Y, Yang L, Wang L, Zhang M, Huang Z, Deng Q, et al. Burden of hypertension in China: A nationally representative survey of 174,621 adults.Int J Cardiol. 2017;227:516-523.

29. Maimaris $\mathrm{W}$, et al. The influence of health systemson hypertension awareness, treatment, and control: a systematicliterature review. PLoS Med. 2013;10:e1001490.

30. Powers BJ, Olsen MK, Oddone EZ,Thorpe CT, Bosworth HB. Literacy and bloodpressure - do healthcare systems influence this relationship? A cross-sectional study. BMC Health Serv Res. 2008;8:1-9. 
31. Hou Z, Meng Q, Zhang Y. Hypertension Prevalence, Awareness, Treatment, and Control Following China's Healthcare Reform. Am J Hypertens. 2016;29:428-431.

32. Zeng XY, Zhang M, Li YC, Huang ZJ, Wang LM. Study on effects of community-based management of hypertension patients aged $\geq 35$ years and influencing factors in urban and rural areas of China, Zhonghua Liu Xing Bing Xue Za Zhi. 2016;37:612-617.

33. Benner JS, Glynn RJ, Mogun H,Neumann PJ, Weinstein MC, Avorn J. Long-term persistence in useof statin therapy in elderly patients. JAMA. 2002;288:455-461.

34. Green BB, et al. Effectiveness of home bloodpressure monitoring, Web communication, and pharmacist care onhypertension control: a randomized controlled trial.

JAMA.2008;299:2857-2867.

35. OheneBuabeng K, Matowe L, Plange-Rhule J. Unaffordable drug prices: the major cause of non-compliance with hypertension medication in Ghana. J Pharm Pharm Sci. 2004;7:350-352.

36. Lager K, Mistri AK.Current status of blood pressure managementafter stroke. Expert Rev Cardiovasc Ther. 2010;8:1587-1598.

37. Ruppar TM, Dunbar-Jacob JM, Mehr DR, Lewis L, Conn VS. Medication adherence interventions among hypertensive black adults: a systematic review and meta-analysis. $J$ Hypertens. 2017;35:1145-1154.

38. Darkins A, et al. Care Coordination/Home Telehealth: the systematic implementation of health informatics, home telehealth, and disease management to support the care of veteran patients with chronic conditions. Telemed J E Health 2008;14:1118-1126.

39. $\mathrm{Yu} \mathrm{CH}$,et al.

Designing and evaluating a web-based self-management site for patients with type 2 diabetes - systematic website development and study protocol. BMC Med Inform Decis Mak. 2012;12:57.

40. Salisbury C, et al. Telehealth for patients at high risk of cardiovascular disease: pragmatic randomised controlled trial. BMJ. 2016;353:i2647.

41. Wootton R. Twenty years of telemedicine in chronic disease management--an evidence synthesis. J TelemedTelecare 2012;18:211-220.

42. Leon N, Surender R, Bobrow K3, Muller J, Farmer A. Improving treatment adherence for blood pressure lowering via mobile phone SMS-mess ages inSouth Africa: a qualitative evaluation of the SMS-text Adherence SuppoRt (StAR) trial. BMC Fam Pract. 2015;16:80.

43. Redfern $\mathrm{J} 1$, et al. A randomised controlled trial of a consumer-focused e-health strategy for cardiovascular riskmanagement in primary care: the Consumer Navigation of Electronic Cardiovascular Tools(CONNECT) study protoco l. BMJ Open. 2014;4:e004523.

44. Shea S, Misra D, Ehrlich MH, Field L, Francis CK. Correlates of nonadherence to hypertension treatment in an inner-city minority population. Am J Public Health. 1992;82:1607-1612.

45. Harmon G, Lefante J, Krousel-Wood MA. Overcoming barriers: the role of providers in improving patient adherence to antihypertensive medications. Curr Opin Cardiol. 
2006;21:310-315.

46. Riddell MA, Joshi R, Oldenburg B, Chow C, Thankappan KR, Mahal A, et al. Cluster randomised feasibility trial to improve the Control of Hypertension In Rural India (CHIRI): a study protocol. BMJ Open. 2016;6:e12404. 